\title{
Analisis Penerimaan Pengguna Garda Sumber Pembelajaran Terbuka Indonesia (Garsupati) Menggunakan Model Unified Theory Of Acceptance And Use Of Technology (UTAUT)
}

\author{
Ella Silviasasmi ${ }^{1}$, I Ketut Resika Arthana ${ }^{2}$, I Made Putrama ${ }^{3}$ \\ Universitas Pendidikan Ganesha, Singaraja, Bali, Indonesia \\ silviasasmie@gmail.com \\ resika@undiksha.ac.id \\ made.putrama@undiksha.ac.id
}

Diterima 12 Maret 2019

Disetujui 24 Juni 2019

\begin{abstract}
The purpose of this research is to know how the user acceptance to Garsupati system so that system development feasible executed. One approach to the theory of acceptance and use of a technology that is Unified Theory Of Acceptance And Use Of Technology (UTAUT). UTAUT is one of the technology acceptance models developed by Vankatesh, et al. (2003) by combining eight previous technology acceptance theories. UTAUT has four main constructs: 1) performance expectancy, 2) effort expectancy, 3) social influence, and 4) facilitating conditions. This research will further explain about the relation of factors influencing acceptance and usage of Garsupati system using UTAUT model. Data were obtained by distributing questionnaires to students and interviews with lecturers. The sample size in this study amounted to 394 Undiksha students, analyzed using multiple linear regression using SPSS software. The results of this study indicate that (1) performance expectation, business expectation, social factor have positive effect to interest of utilization of Garsupati system (2) facility factor and interest of utilization have positive effect to user behavior.
\end{abstract}

Keywords: Open Educational Resources, Garsupati, UTAUT

\section{PENDAHULUAN}

Perkembangan teknologi telah memberikan pengaruh yang besar dalam dunia pendidikan, salah satunya yaitu internet. Internet dapat menjadi salah satu cara untuk mengembangkan dan penyebaran ilmu pengetahuan. Sebagai contoh, dalam pembelajaran guru/dosen dapat memanfaatkan internet sebagai sumber pembelajaran dalam mendukung tercapainya kompetensi suatu mata kuliah. Permasalahan yang muncul yaitu sulitnya mengidentifikasi dan mengaitkan antar materi serta melakukan pencarian sumber pembelajaran terbuka. Sulitnya mencari sumber pembelajaran terbuka karena sumber pembelajaran terbuka tersebut dipublikasikan melalui situs yang berbeda-beda(Dantes \& Arthana, 2016).
Sumber pembelajaran yang digunakan secara bebas yang dimanfaatkan untuk meningkatkan ilmu pengetahuan disebut dengan Sumber Pembelajaran Terbuka atau Open Educational Resource (OER). OER dapat berupa materi, modul, buku teks, video, materi interaktif seperti simulasi dan bahan pendidikan lainnya. OER telah didukung Pemerintah Indonesia dalam Undang-Undang No 12 Tahun 2012 Tentang Pengembangan Perguruan Tinggi pasal 79 ayat 4 menyebutkan Pemerintah mengembangkan sumber pembelajaran terbuka yang dapat dimanfaatkan oleh seluruh Sivitas Akademika.

Adapun penelitian pengembangan yang sedang dikembangkan terkait OER adalah Garda Sumber Pembelajaran Terbuka Indonesia (Garsupati). Garsupati merupakan satu sistem OER dimana dalam sistem tersebut pengguna dapat mencari sumber pembelajaran dan materi-materi yang saling berkaitan.

Agar developer dapat menganalisa kebutuhan pengguna ketika menggunakan sistem Garsupati, penting dilakukan Feasibility Study untuk mengetahui bagaimana penerimaan pengguna terhadap sistem tersebut sehingga pengembangan sistem layak dilaksanakan. Sebelum sistem dikembangkan penting untuk mengetahui apakah konsep dari sistem yang dikembangkan dapat diterima atau tidak. Untuk mengetahui tingkat penerimaan calon pengguna terhadap sistem yang akan dikembangkan dapat diukur menggunakan salah satu pendekatan teori penerimaan dan penggunaan terhadap suatu teknologi. Salah satu cara untuk mengukur penerimaan teknologi yaitu UTAUT. TAM dan UTAUT merupakan model penerimaan teknologi yang paling sering digunakan. TAM dikembangkan untuk menjelaskan perilaku pengguna sistem informasi atau teknologi yang menempatkan faktor sikap dan tiap-tiap perilaku pemakai dengan konstruk yaitu persepsi kegunaan (perceived usefulness), kemudahan penggunaan (perceived ease of use) dan kondisi nyata pengguna sistem (actual system usage). Sedangkan metode 
UTAUT paling banyak digunakan dalam penelitian pengukuran kesuksesan penerepan sistem informasi yang berkaitan dengan Akademik. UTAUT menempatkan faktor-faktor yang mempengaruhi seseorang dalam menggunakan suatu sistem informasi atau teknologi dengan konstruk ekspektasi kinerja (performance expectancy), ekspektasi usaha (effort expectancy), Pengaruh social (social influence), Kondisi fasilitas (facilitating condition) dan penggunaan teknologi sesungguhnya (actual system usage) (Hamrul, Soedijono, \& Amborowati, 2013).

Pada penelitian ini akan dilakukan pengujian penerimaan terhadap Garsupati sehingga diketahui apakah ekspektasi kinerja, ekspektasi usaha, pengaruh sosial dan kondisi yang memfasilitasi berpengaruh terhadap minat pengguna sistem Garsupati. Berdasarkan hal tersebut peneliti akan melakukan penelitian tentang "ANALISIS PERILAKU PENGGUNA GARDA SUMBER PEMBELAJARAN TERBUK INDONESIA (GARSUPATI) MENGGUNAKAN MODEL UNIFIED THEORY OF ACCEPTANCE AND USE OF TECHNOLOGY

\section{(UTAUT) $"$ \\ II. KAJIAN PUSTAKA}

A. Open Educational Resources (OER)

Open educational resources merupakan sumber pembelajaran, pengajaran dan penelitian berada dalam domain publik atau dirilis sesuai dengan lisensi hak kekayaan intelektual yang mengijinkan untuk digunakan, diadaptasi dan didistribusikan secara bebas (UNESCO, 2012). OER dikategorikan menjadi tiga kategori yaitu Open Content, Open CourseWare dan Open Campus (Indrajit, 2014).

\section{B. Garda Sumber Pembelajaran Terbuka Indonesia (Garsupati)}

Garsupati merupakan satu contoh OER dimana dalam sistem tersebut pengguna dapat mencari sumber pembelajaran dan materi-materi yang saling berkaitan. Garsupati berfungsi sebagai pintu gerbang menuju sumber pembelajaran terbuka. Dalam sistem Garsupati pengguna dapat mencari sumber belajar berupa konten ajar maupun courseware dimana pengguna bisa mencari berdasarkan bidang ilmu atau educational level, melihat detail sumber ajar dan courseware, memberikan penilaian dan komentar terkait konten ajar maupun courseware, melaporkan konten ajar dan courseware yang tidak sesuai. Sedangkan kontributor bisa menyumbangkan konten ajar baik secara penuh atau sumber ajar yang ada pada situs lain, dan juga dapat membuat courseware dengan menggabungkan sumber-sumber pembelajaran yang ada pada sistem Garsupati dan admin bisa memoderasi sumber ajar yang didaftarkan pada Garsupati.

\section{Unified Theory Of Acceptance And Use Of} Technology (UTAUT)

UTAUT merupakan salah satu model penerimaan teknologi dengan menggabungkan fitur-fitur dari delapan teori penerimaan teknologi sebelumnya. Delapan teori tersebut adalah theory of reasoned action (TRA), technology acceptance model (TAM), motivational model (MM), theory of palnned behavior (TPB), Combined TAM and TPB, model of PC utilization (MPTU), innovation diffusion theory (IDT) dan social cognativetheory (SCT) (Venkatesh, Morris, Davis, \& Davis, 2003).

UTAUT memiliki empat konstruk utama yaitu 1) ekspektansi kinerja (performance expectancy), 2) ekspektansi usaha (effort expectancy), 3) pengaruh sosial (social influence), dan 4) kondisi-kondisi pemfasilitasi (facilitating conditions). Selain empat konstruk tersebut, terdapat empat moderator yang memoderasi dampak dari empat konstruk utama pada behavioral intention dan use behavior yaitu gender, age, voluntariness, dan experience.

\section{Metode Penelitian}

\section{A. Jenis penelitian}

Penelitian ini merupakan penelitian survei. Lokasi penelitian merupakan tempat dilaksanakannya penelitian. Penelitian ini dilaksanakan di Universitas Pendidikan Ganesha (Undiksha) dimana subjek yang diteliti yaitu mahasiswa dan dosen di lingkungan Undiksha. Waktu penelitian ini adalah tahun 20172018.

Populasi dalam penelitian ini adalah pengguna sistem Garsupati yaitu mahasiswa dan dosen di lingkungan Universitas Pendidikan Ganesha yang berjumlah 27530 mahasiswa. Sedangkan sampel pada penelitian ini dihitung menggunakan rumus sebagai berikut :

$$
\begin{aligned}
& n=\frac{N}{1+N e^{2}} \quad \ldots \ldots \ldots \ldots \ldots \ldots \\
& n=\frac{27530}{1+27530(0,05)^{2}}=394,27
\end{aligned}
$$

Berdasarkan hasil perhitungan diatas, maka jumlah sampel dalam penelitian ini berjumlah 394 mahasiswa. Teknik pengumpulan data dalam penelitian ini yaitu wawancara yang dilakukan bersama dosen dan kuesioner yang disebarkan kepada mahasiswa.

Contoh pernyataan untuk responden penelitian :

a. Ekspektasi kinerja : Garsupati memberikan manfaat bagi saya dalam mendapatkan materi pelajaran

b. Ekspektasi usaha : Saya merasa ketika nanti saya menggunakan sistem Garsupati saya bisa menggunakan tanpa melalui training 
c. Faktor Sosial : Ketertarikan saya pada Garsupati berawal dari postingan teman di media sosial

d. Kondisi yang Memfasilitasi : Saya memiliki perangkat yang diperlukan untuk menggunakan sistem Garsupati

\section{B. Uji Coba Instrumen Penelitian \\ B.1 Uji Validitas}

Untuk menguji validitas adalah menggunakan rumus korelasi product moment sebagai berikut :

$$
\mathrm{r}_{\mathrm{xy}}=\frac{N \Sigma X Y-(\Sigma X)(\Sigma Y)}{\sqrt{\left[N \Sigma X^{2}-\left(\Sigma X^{2}\right)\right\}\left\{N \Sigma Y^{2}-\left(\Sigma Y^{2}\right)\right\}}}
$$

Keterangan :

$\mathrm{r}_{\mathrm{xy}}$ : Koefisien korelasi product moment

$\mathrm{N}$ : Jumlah responden

$\mathrm{X}$ : Skor variabel (Jawaban responden)

$\mathrm{Y}$ : Skor total dari variabel untuk responden ke-N

Untuk mengetahui validitas butir, koefisien korelasi product moment $\left(\mathrm{r}_{\mathrm{xy}}\right)$ dibandingkan dengan harga $r_{\text {tabel }}$. Jika $r_{x y}>r_{\text {tabel }}$ maka butir dinyatakan valid karena terdapat korelasi yang signifikan antara skor butir dengan skor total.

\section{B.2 Uji Reliabilitas}

Tahapan perhitungan uji reliabilitas dengan menggunakan teknik alpha cronbach, yaitu (Siregar, 2015):

a. Menentukan nilai varian setiap butir pertanyaan

$$
\sigma_{i}^{2}=\frac{\Sigma X_{i}^{2}-\frac{\left(\Sigma X_{i}\right)^{2}}{n}}{n}
$$

b. Menentukan nilai varian total

$$
\sigma_{t}^{2}=\frac{\Sigma X^{2}-\frac{(\Sigma X)^{2}}{n}}{n}
$$

c. Menentukan reliabilitas instrumen

$$
\mathrm{r}_{11}=\frac{(k)}{(k-1)}\left(1-\frac{\Sigma \sigma b^{2}}{\sigma^{2} t}\right)
$$

Keterangan :

$$
\begin{array}{ll}
\mathrm{r} 11 & =\text { koefisien reliabilitas instrument } \\
\mathrm{n} & =\text { Jumlah sampel } \\
\mathrm{k} & =\text { jumlah butir pertanyaan } \\
\Sigma \sigma \mathrm{b}^{\wedge} 2 & =\text { jumlah varians butir } \\
\sigma^{\wedge} 2 \mathrm{t} & =\text { varians total } \\
\Sigma \mathrm{X} & =\text { Total jawaban responden untuk } \\
& \text { setiap butir pertanyaan }
\end{array}
$$

$\mathrm{Xi}$

=Jawaban responden untuk setiap butir pertanyaan

\section{B.3 Analisis Data}

Dalam penelitian kuantitatif, teknik analisis data diarahkan untuk menjawab rumusan masalah atau menguji hipotesis yang telah dirumuskan. Pengujian hipotesis yang digunakan dalam penelitian ini adalah analisis regresi dengan model umum persamaan regresi sebagai berikut :

$$
\mathrm{Y}=\alpha+b_{1} X_{1}+b_{2} X_{2}+b_{3} X_{3}+b_{4} X_{4}+\varepsilon
$$

\section{Keterangan :}

$\begin{array}{ll}\mathrm{Y} & \text { : Keuntungan } \\ \alpha & \text { : Konstanta } \\ \text { b1 b2 b3 b4 } & \text { : Koefisien regresi } \\ \mathrm{X} 1 & \text { : Ekspektasi kinerja } \\ \mathrm{X} 2 & : \text { Ekspektasi Usaha } \\ \mathrm{X} 3 & : \text { Faktor sosial } \\ \mathrm{X} 4 & : \text { Kondisi yang memfasilitasi } \\ \varepsilon & : \text { Error }\end{array}$

\section{HASIL DAN PEMBAHASAN}

A. Uji Hipotesis $(U j i t)$

Hipotesis :

H0: (Variabel bebas ke-i tidak berpengaruh signifikan terhadap variabel

H1 : (Variabel bebas ke-i berpengaruh signifikan terhadap variabel terikat)

(dengan $\mathrm{i}=1,2,3$ )

Tingkat signifikansi $: 0,05$

Keputusan Uji : tolak H0 jika nilai sig.

variabel ke-i $<0,05$

Tabel 1 Nilai Uji t Berdasarkan Behavioral Intention untuk Dosen

\begin{tabular}{|c|r|r|}
\hline Model & \multicolumn{1}{|c|}{$\mathrm{t}$} & \multicolumn{1}{c|}{ Sig. } \\
\hline (Constant) & $-3,008$ &, 006 \\
Performance Expectancy & 2,924 &, 007 \\
Effort Expectancy & 4,212 &, 000 \\
Social Influence & 2,876 &, 008 \\
\hline
\end{tabular}


Tabel 2 Nilai Uji t Berdasarkan Use Behavior untuk Dosen

\begin{tabular}{|c|r|r|}
\hline Model & \multicolumn{1}{|c|}{$\mathrm{t}$} & \multicolumn{1}{c|}{ Sig. } \\
\hline (Constant) & $-6,577$ &, 000 \\
Facilitating Condition & 10,317 &, 000 \\
Behavioral Intention & 2,583 &, 016 \\
\hline
\end{tabular}

Tabel 3. Nilai Uji t Berdasarkan Behavioral Intention untuk Mahasiswa

\begin{tabular}{|c|r|r|}
\hline Model & \multicolumn{1}{|c|}{$\mathrm{t}$} & \multicolumn{1}{c|}{ Sig. } \\
\hline (Constant) & $-11,513$ &, 000 \\
Performance Expectancy & 6,915 &, 000 \\
Effort Expectancy & 6,265 &, 000 \\
Social Influence & 9,164 &, 000 \\
\hline
\end{tabular}

Tabel 4. Nilai Uji t Berdasarkan Use Behavior untuk Mahasiswa

\begin{tabular}{|c|c|c|c|c|}
\hline \multicolumn{2}{|c|}{$\begin{array}{c}\text { Uji t Berdasarkan } \\
\text { Behavioral Intention }\end{array}$} & \multicolumn{2}{|c|}{$\begin{array}{c}\text { Nilai Uji t } \\
\text { Berdasarkan Use } \\
\text { Behavior }\end{array}$} & \multirow{2}{*}{ Kesimpulan } \\
\cline { 1 - 3 } Dosen & Mahasiswa & Dosen & Mahasiswa & \\
\hline 0,006 & 0,000 & 0,000 &, 000 & Berpengaruh \\
\hline 0,007 & 0,000 & 0,000 &, 000 & Berpengaruh \\
\hline 0,000 & 0,000 & 0,016 &, 000 & Berpengaruh \\
\hline 0,008 & 0,000 & & & Berpengaruh \\
\hline
\end{tabular}

\section{B. Kesimpulan Hasil}

Tabel 5. Hasil Uji Hipotesis

\begin{tabular}{|c|r|r|}
\hline Model & \multicolumn{1}{|c|}{$\mathrm{t}$} & Sig. \\
\hline (Constant) & 16,093 &, 000 \\
Facilitating Condition & 5,145 &, 000 \\
Behavioral Intention & 41,444 &, 000 \\
\hline
\end{tabular}

C. Pembahasan Hasil Uji Regresi Berdasarkan Behavioral Intention

Terdapat tiga hipotesis yang ditemukan dari hasil uji regresi berdasarkan behavioral intention :

1. Pengaruh Performance Expectancy (PE) terhadap minat pemanfaatan (behavioral intention) sistem Garsupati

Ekspektasi kinerja (Performance Expectancy) dosen mempunyai nilai Sig $=0,007$ dengan koefisien regresi sebesar 0,301. Sedangkan untuk mahasiswa mempunyai nilai $\mathrm{Sig}=0,000$ dengan koefisien regresi sebesar 0,254 yaitu hipotesis diterima bahwa faktor ekspektasi kinerja berpengaruh positif terhadap minat pemanfaatan (behavioral intention) sistem Garsupati.

Ekspektasi kinerja bagi dosen dan mahasiswa dalam penelitian ini yaitu berhubungan dengan kegunaan, motivasi, kesesuaian sistem dengan pekerjaan dan keuntungan yang didapatkan ketika nanti menggunakan sistem tersebut.

2. Pengaruh Effort Expectancy terhadap minat pemanfaatan (behavioral intention) sistem Garsupati

Ekspektasi usaha (Effort Expectancy) mempunyai nilai Sig $=0,000$ den gan koefisien regresi sebesar 0,472 . Sedangkan untuk mahasiswa mempunyai nilai $\mathrm{Sig}=0,000$ dengan koefisien regresi sebesar 0,274 yaitu hipotesis diterima bahwa faktor ekspektasi usaha berpengaruh positif terhadap minat pemanfaatan (behavioral intention) sistem Garsupati.

Ekspektasi usaha dalam penelitian ini yaitu kemudahan yang dirasakan pengguna, kerumitan dan kemudahan penggunaan sistem Garsupati yang dapat memudahkan pengguna dalam berbagi dan mencari materi ajar.

3. Pengaruh Social Influence terhadap minat pemanfaatan (behavioral intention) sistem Garsupati

Faktor sosial (Social Influence) mempunyai nilai Sig $=0,008$ dengan koefisien regresi sebesar 0,334 . Sedangkan untuk mahasiswa mempunyai nilai Sig $=0,000$ dengan koefisien regresi sebesar 0,407 yaitu hipotesis diterima bahwa faktor sosial berpengaruh positif terhadap minat pemanfaatan (behavioral intention) sistem Garsupati.

Faktor sosial dalam penelitian ini yaitu sejauh mana seseorang dipengarui oleh orang lain untuk menggunakan suatu sistem informasi yang dalam penelitian ini yaitu sistem Garsupati.

\section{Pembahasan Hasil Uji Regresi Berdasarkan Use Behavior}

Terdapat dua hipotesis yang ditemukan dari hasil uji regresi berdasarkan use behavior :

1. Kondisi yang memfasilitasi terhadap perilaku penggunaan (Use Behavior)

Faktor fasilitas (Facilitating Condition) mempunyai nilai Sig $=0,000$ dengan koefisien regresi sebesar 0,818 . Sedangkan untuk mahasiswa mempunyai mempunyai nilai Sig $=0,000$ dengan koefisien regresi sebesar 0,108 yaitu hipotesis diterima bahwa faktor fasilitas berpengaruh positif terhadap perilaku pengguna (Use Behavior) sistem Garsupati

Faktor fasilitas dalam penelitian ini yaitu persepsi kendala internal dan eksternal terhadap 
perilaku, fasilitas seperti komputer dan jaringan internet juga kesesuaian dengan kebutuhan.

2. Minat pemanfaatan (behavioral intention) terhadap perilaku penggunaan (Use Behavior)

Minat pemanfaatan (behavioral intention) mempunyai nilai $\mathrm{Sig}=0,016$ dengan koefisien regresi sebesar 0,205. Sedangkan untuk mahasiswa mempunyai nilai Sig $=0,000$ dengan koefisien regresi sebesar 0,874 yaitu hipotesis diterima bahwa minat pemanfaatan berpengaruh positif terhadap perilaku pengguna (Use Behavior) sistem Garsupati.

Minat pemanfaatan dalam penelitian ini yaitu tingkat keinginan atau niat untuk menggunakan teknologi informasi yang dapat mempengaruhi tingkat kinerja pengguna. Dalam hal ini pengguna mempunyai keinginan menggunakan sistem Garsupati untuk waktu yang akan datang.

\section{SIMPULAN}

Berdasarkan hasil analisis dan pembahasan maka dapat disimpulkan bahwa semua hipotesis dalam penelitian ini diterima yaitu :

1. Ekspektasi kinerja (Performance Expectancy), Ekspektasi usaha (Effort Expectancy), dan Faktor sosial (Social Influence) berpengaruh positif terhadap minat pemanfaatan (behavioral intention).

2. Faktor fasilitas (Facilitating Condition) dan minat pemanfaatan (behavioral intention) berpengaruh positif terhadap perilaku pengguna (Use Behavior) sistem Garsupati yaitu pengguna mempunyai keinginan menggunakan sistem Garsupati untuk waktu yang akan datang. Dengan demikian bahwa tingginya kepercayaan seseorang untuk menggunakan sistem Garsupati dapat meningkatkan kinerja dan mengurangi usaha akan meningkatkan minat untuk memanfaatkan sistem Garsupati, minat pemanfaatan juga dipengaruhi oleh lingkungan sekitarnya. Sedangkan perilaku pengguna dipengaruhi oleh fasilitas yang ada, dengan adanya fasilitas yang dibutuhkan untuk menggunakan sistem maka akan semakin sering pengguna menggunakan sistem tersebut.
3. Berdasarkan hasil penelitian dimana semua hipotesis diterima yang berarti bahwa sistem Garsupati dapat diterima oleh calon pengguna dilihat dari minat penggunaan dan perilaku pengguna. Intensitas dalam penggunaan sistem Garsupati dalam satu hari yaitu 60-75 menit dengan frekuensi penggunaan sekali atau dua kali dalam seminggu dan sekali atau dua kali dalam dua minggu untuk dosen. Sedangkan banyaknya fitur yang akan sering digunakan oleh pengguna yaitu ada tiga jenis fitur untuk mahasiswa dan dua jenis fitur untuk dosen.

4. Dari hasil penelitian ini developer dapat menganalisa kebutuhan pengguna ketika menggunakan sistem Garsupati dan dapat mengetahui apa yang mempengaruhi user menggunakan sistem Garsupati.

5. Dari penelitian ini, peneliti memberikan saran bahwa peneliti selanjutnya dapat menganalisa faktor-faktor lain yang dapat mempengaruhi pengguna untuk meggunakan sebuah sistem informasi

\section{DAFTAR PUSTAKA}

[1] Dantes, G. R., \& Arthana, I. K. R. (2016). Peran Guru dan Dosen dalam Sumber Pembelajaran Terbuka Indonesia. Prosiding Seminar Nasional Pendidikan Teknik Informatika (SENAPATI 2016), 10-14.

[2] Hamrul, H., Soedijono, B., \& Amborowati, A. (2013). Mengukur Kesuksesan Penerapan Sistem Informasi Akademik (Studi Kasus Penerapan Sistem Informasi Stmik Dipanegara Makassar ). Seminar Nasional Informatika 2013, 2013(semnasIF), 140-146.

[3] Indrajit, R. E. (2014). APTIKOM OPEN EDUCATION ARCHITECTURAL FRAMEWORK.

[4] Siregar, S. (2015). Statistik Parametik untuk Penelitian Kuantitatif. Jakarta: PT Bumi Aksara.

5] Venkatesh, V., Morris, M. G., Davis, G. B., \& Davis, F. D. (2003). User Acceptance of Information Technology: Toward a Unified View Author ( s ): Viswanath Venkatesh, Michael G . Morris, Gordon B . Davis, Fred D . Davis Published by : Management Information Systems Research Center , University of Minnesota, 27(3), 425-478. 